\title{
EFEITOS DAS CONDIÇÕES DE AMADURECIMENTO SOBRE A SUSCETIBILIDADE DE BANANAS 'SH 3640' AO DESPENCAMENTO NATURAL'
}

\author{
VICTOR MARTINS MAIA², RODRIGO SOBREIRA ALEXANDRE 3 , LUIZ CARLOS CHAMHUM SALOMÃO ${ }^{4}$, \\ ELDO ANTÔNIO MONTEIRO DA SILVA 5 , RENATA MARIA STROZI ALVES MEIRA ${ }^{6}$
}

\begin{abstract}
RESUMO - Com o objetivo de verificar os efeitos das condições de amadurecimento sobre o despencamento natural de bananas 'SH 3640', foi instalado um experimento segundo delineamento inteiramente casualizado, com quatro tratamentos: T1 - amadurecimento em temperatura ambiente $\left(24,6 \pm 1,7^{\circ} \mathrm{C}\right)$; $\mathrm{T} 2$ - pré-condicionamento dos frutos a $5^{\circ} \mathrm{C}$ por 6 horas, seguido de amadurecimento em temperatura ambiente; $\mathrm{T} 3$ - pré-condicionamento dos frutos a $5^{\circ} \mathrm{C}$ por 12 horas, seguido de amadurecimento em temperatura ambiente; $\mathrm{T} 4$ - amadurecimento dos frutos em sacos de polietileno de baixa densidade a $18^{\circ} \mathrm{C}$. Foram utilizadas 6 repetições para as observações anatômicas e 4 repetições para as avaliações de resistência ao despencamento, consistência da polpa do fruto maduro e do tempo entre a colheita e o amadurecimento, sendo cada repetição constituída de um fruto. Os frutos dos tratamentos T2 e T4 apresentaram maior resistência ao despencamento natural, o que é justificado pelo aumento da espessura e pela maior deposição de lignina nas paredes celulares. Os frutos do tratamento T4 tiveram o amadurecimento retardado em relação aos demais. Os frutos dos diversos tratamentos não diferiram quanto à consistência da polpa.
\end{abstract}

Termos para indexação: Musa spp., pós-colheita, temperatura, caracterização anatômica.

\section{EFFECTS OF RIPENING CONDITIONS ON SUSCEPTIBILITY OF ‘SH 3640’ BANANA TO FINGER DROP}

ABSTRACT - Aiming to verify the effects of the ripening conditions on the finger drop of bananas 'SH 3640', this experiment was set up on an entirely randomized design, with four treatments: $\mathrm{T} 1$ - ripening under environmental temperature $\left(24.6 \pm 1.7^{\circ} \mathrm{C}\right)$; $\mathrm{T} 2$ - preconditioning of the fruits at $5^{\circ} \mathrm{C}$ for 6 hours, following the ripening under environmental temperature; $\mathrm{T} 3$ - preconditioning of the fruits at $5^{\circ} \mathrm{C}$ for 12 hours, following the ripening under environmental temperature; and T4 - ripening of the fruits in low-density polyethylene bags at $18^{\circ} \mathrm{C}$. Six replicates were used for the anatomical observations, and 4 replicates for evaluating the resistance to finger drop, pulp consistence of the ripe fruit and the number of days from harvest to ripening, with each replicate consisting of one fruit. The fruits of treatments T2 and T4 showed higher resistance to finger drop, what is justified by the increase in either thickness and the highest lignin deposition in the cellular wall. Fruits of treatment T4 showed a delayed ripening, comparing to the others's. The fruits of all treatments showed no differences for consistence of the pulp.

Index terms: Musa spp., post-harvest, temperature, anatomical characterization.

O despencamento ou queda natural de frutos é um dos maiores problemas pós-colheita da banana, restringindo a comercialização. Este fenômeno é resultado do amolecimento e enfraquecimento fisiológico do pedicelo, que leva à separação individual dos frutos da penca com muita facilidade (New e Marriott, 1983).

A bananeira 'SH 3640' (AAAB), híbrido da 'Prata-Anã' criado pela Fundación Hondureña de Investigación Agrícola (FHIA), de Honduras, apresenta porte baixo e alta produtividade (Cerqueira et al., 2002), mas é suscetível ao despencamento natural (Pereira, 2002). Neste estudo, objetivou-se verificar os efeitos do pré-condicionamento e amadurecimento dos frutos a baixa temperatura sobre a suscetibilidade da banana 'SH 3640' ao despencamento natural.

Dois cachos de bananas no estádio 3/4 natural (Lichtemberg, 1999) foram colhidos na Fazenda Experimental da Sementeira, de propriedade da Universidade Federal de Viçosa, e transportados para o Laboratório de Análise de Frutas do Departamento de Fitotecnia. Foram utilizadas a segunda e a terceira pencas de cada cacho, que foram lavadas em água corrente e imersas em solução contendo $500 \mathrm{mg} \mathrm{L}^{-1}$ de ethephon (Ethrel, Rhône-Poulene Agro Brasil Ltda.) por 10 minutos.

O experimento foi instalado segundo delineamento inteiramente casualizado, com 4 tratamentos: T1 - amadurecimento em temperatura ambiente $\left(24,6 \pm 1,7^{\circ} \mathrm{C}\right.$ e umidade relativa de $\left.84,8 \pm 3,1 \%\right)$; T2 - précondicionamento dos frutos a $5^{\circ} \mathrm{C}$ por 6 horas, seguido de amadurecimento em temperatura ambiente; $\mathrm{T} 3$ - pré-condicionamento dos frutos a $5^{\circ} \mathrm{C}$ por 12 horas, seguido de amadurecimento em temperatura ambiente; T4 - amadurecimento dos frutos em sacos de polietileno de baixa densidade $\mathrm{a} 18^{\circ} \mathrm{C}$. Foram utilizadas 6 repetições para as observações anatômicas e 4 repetições para as avaliações de resistência ao despencamento, consistência da polpa do fruto maduro e número de dias da colheita até o amadurecimento, ou seja, até atingir o estádio de cor da casca 6 (Dadzie e Orchard, 1997), sendo cada repetição constituída de um fruto.

A consistência da polpa foi determinada de acordo com Dadzie e Orchard (1997), e a resistência ao despencamento foi determinada com o auxílio de um despencador manual (Cerqueira, 2000).

Para as observações anatômicas, secções de um centímetro de comprimento da região do pedicelo onde ocorre o despencamento natural, foram obtidas, conforme descrição de Pereira (2002). Cada pedicelo foi

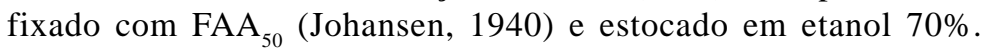
Posteriormente, cada um foi seccionado longitudinalmente em seis partes, aproveitando-se duas delas para os cortes anatômicos transversal e longitudinal (Pereira, 2002). Os cortes foram obtidos em um micrótomo de mesa e corados com fucsina básica e azul de astra (Kraus e Arduim, 1997). As lâminas foram montadas com gelatina glicerinada (Johansen, 1940).

As análises e documentações fotográficas foram efetuadas em microscópio fotônico Olympus AX 70, pertencente ao Laboratório de Anatomia Vegetal do Departamento de Biologia Vegetal. As características avaliadas foram a distribuição e a coloração dos componentes dos tecidos da região em que ocorre o despencamento natural dos frutos.

Os dados obtidos foram submetidos à análise de variância. As médias dos fatores foram comparadas, utilizando-se do teste de Tukey, a $5 \%$ de probabilidade.

$\mathrm{O}$ acondicionamento em sacos de polietileno a $18{ }^{\circ} \mathrm{C}(\mathrm{T} 4)$ retardou o amadurecimento dos frutos em relação àqueles précondicionados a $5{ }^{\circ} \mathrm{C}$ por 6 e 12 horas (T2 e T3, respectivamente) (Tabela 1). Os frutos sujeitos a estes tratamentos (T2 e T3) apresentaram sintomas

\footnotetext{
${ }^{1}$ (Trabalho 132/2003). Recebido: 12/09/2003. Aceito para publicação: 02/07/2004.

2 Eng. Agr ${ }^{\circ}$, Doutorando em Fitotecnia, UFV, Viçosa, MG, 36570-000 - (31) 3899-2641 - vmaia@alunos.ufv.br - Bolsista do CNPq.

${ }^{3}$ Eng. Agr ${ }^{\circ}$, Doutorando em Fitotecnia, UFV, Viçosa, MG, 36570-000 - (31) 3899-2641 - rsalexandre@ click21.com.br - Bolsista da CAPES.

${ }^{4}$ Professor Adjunto, Depart ${ }^{\circ}$ de Fitotecnia, UFV, Viçosa, MG, 36570-000 - (31) 3899-1350 - lsalomao@ufv.br - Bolsista do CNPq.

${ }^{5}$ Professor Titular, Depart ${ }^{\circ}$ de Biologia Vegetal, UFV, Viçosa, MG, 36570-000 - (31) 3899- 1290.

${ }^{6}$ Professor Adjunto, Depart ${ }^{\circ}$ de Biologia Vegetal, UFV, Viçosa, MG, 36571-000 - (31) 3899-2584. rmeira@ufv.br
} 
característicos de injúria por frio, como o escurecimento subepitelial da casca, o que é prejudicial para a comercialização, uma vez que o consumidor rejeita frutos com aparência desagradável. Em função desta injúria, houve, provavelmente, um estímulo à síntese de etileno (Buchanan et al., 2000), acelerando o amadurecimento dos frutos.

Com relação à consistência da polpa, não foi observada diferença estatística entre os tratamentos aplicados (Tabela 1), confirmando, juntamente com o estádio de cor da casca, que os frutos estavam homogêneos quanto aos estádios de maturação no período das avaliações.

TABELA 1 - Número de dias da colheita até o amadurecimento (índice de cor da casca 6), consistência da polpa (MPa) e resistência ao despencamento $(\mathrm{N})$ (índice de cor da casca 6) de bananas 'SH 3640' amadurecidas ao ambiente (T1), ao ambiente após pré-condicionamento dos frutos a $5^{\circ} \mathrm{C}$ por 6 horas (T2) e 12 horas (T3) e em sacos de polietileno de baixa densidade a $18^{\circ} \mathrm{C}(\mathrm{T} 4)$.

\begin{tabular}{lcc}
\hline & Tratamentos & Médias \\
\hline & 1 & $08,5 \mathrm{ab}$ \\
Dias até o amadurecimento & 2 & $07,5 \mathrm{~b}$ \\
& 3 & $07,8 \mathrm{~b}$ \\
& 4 & $10,0 \mathrm{a}$ \\
\hline $\mathrm{CV}(\%)$ & & 15,58 \\
\hline & 1 & $0,072 \mathrm{a}$ \\
Consistência da polpa (MPa) & 2 & $0,074 \mathrm{a}$ \\
& 3 & $0,078 \mathrm{a}$ \\
\hline CV (\%) & 4 & $0,080 \mathrm{a}$ \\
\hline \multirow{2}{*}{ Resistência ao } & & 10,03 \\
despencamento (N) & 1 & $17,29 \mathrm{bc}$ \\
& 2 & $15,08 \mathrm{c}$ \\
CV (\%) & 3 & $23,18 \mathrm{ab}$ \\
\hline As & 4 & $25,02 \mathrm{a}$ \\
\hline
\end{tabular}

As médias seguidas por uma mesma letra na coluna não diferem entre si, ao nível de $5 \%$ de probabilidade, pelo teste de Tukey.

Os frutos que amadureceram a $18^{\circ} \mathrm{C}(\mathrm{T} 4)$ e os mantidos a $5^{\circ} \mathrm{C}$ por 12 horas antes do amadurecimento ao ambiente (T3), mostraram-se mais resistentes ao despencamento que os dos demais tratamentos (Tabela 1). Nos frutos destes tratamentos, houve maior deposição de lignina nas paredes das fibras perivasculares dos feixes da região do pedicelo do fruto, conforme evidenciado pela coloração mais intensa e de maior espessura da parede celular em relação aos demais tratamentos (Figura 1).

A síntese e a deposição de lignina podem dar-se em resposta a estresses (Buchanan et al., 2000), como, por exemplo, a injúria por frio. Uma vez que a lignina está envolvida no mecanismo de resistência a esta injúria (Mulas et al., 1996), sugere-se que o pré-condicionamento do fruto em câmara fria a $5^{\circ} \mathrm{C}$ por 12 horas e o amadurecimento do fruto a 18 ${ }^{\circ} \mathrm{C}$ promoveram estresse no fruto suficiente para estimular a biossíntese de lignina, o que não se observou quando os frutos foram précondicionados a $5^{\circ} \mathrm{C}$ por apenas 6 horas .

Neste experimento, os valores médios de resistência ao despencamento encontrados nos tratamentos 1 e $2(17,29 \mathrm{~N}$ e 15,08 N, respectivamente) foram semelhantes aos encontrados por Pereira (2002) para o mesmo genótipo $(14,4 \mathrm{~N})$, o qual classificou como suscetível ao despencamento. Quando os frutos foram submetidos a condições de amadurecimento de $18{ }^{\circ} \mathrm{C}$ e envoltos por sacos de polietileno (T4) ou 5 ${ }^{\circ} \mathrm{C}$ por 12 horas e amadurecimento ao ambiente (T3), obtiveram-se valores de resistência ao despencamento de $25,02 \mathrm{~N}$ e $23,18 \mathrm{~N}$, respectivamente, o que eleva sua classificação para medianamente resistentes ao despencamento, segundo o mesmo autor.

Diante desses resultados, conclui-se que o précondicionamento dos frutos a $5{ }^{\circ} \mathrm{C}$ por 12 horas, seguido de amadurecimento à temperatura ambiente (T3), e o amadurecimento em polietileno de baixa densidade a $18^{\circ} \mathrm{C}(\mathrm{T} 4)$ aumentaram a resistência de bananas 'SH 3640' ao despencamento natural em conseqüência do aumento da espessura e da maior deposição de lignina nas paredes das fibras perivasculares.

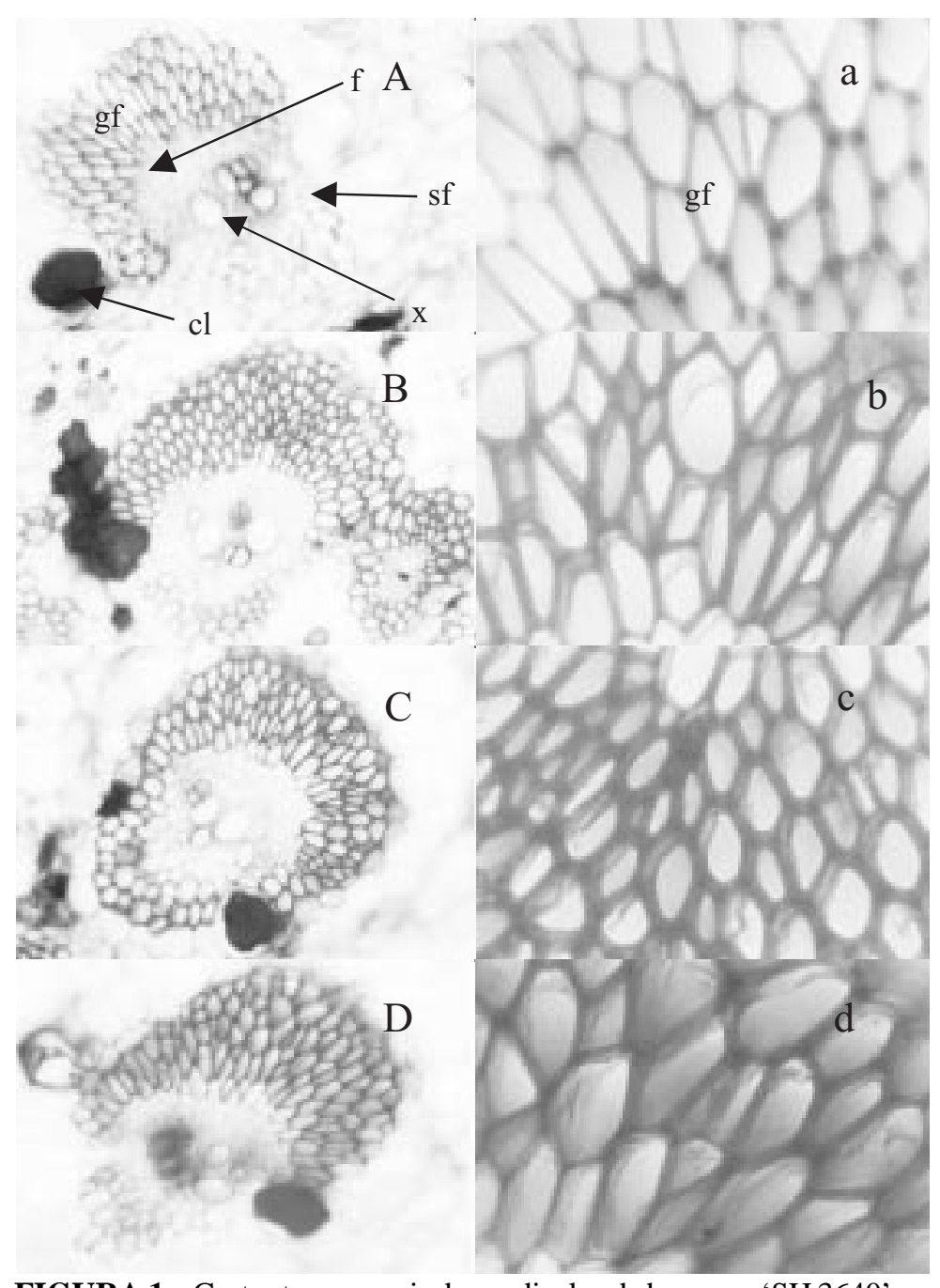

FIGURA 1 - Cortes transversais dos pedicelos de bananas 'SH 3640' no índice de cor da casca 6, amadurecidas ao ambiente (T1) (cortes A, a), ao ambiente após pré-condicionamento dos frutos em câmara fria $5^{\circ} \mathrm{C}$ por 6 horas (T2) (cortes B, b) e 12 horas (T3) (cortes $\mathrm{C}, \mathrm{c}$ ) horas e em sacos de polietileno de baixa densidade a $18^{\circ} \mathrm{C}(\mathrm{T} 4)$ (cortes $\left.\mathrm{D}, \mathrm{d}\right)$, indicando aumento da espessura das paredes do sistema fibrovascular (sf) devido à deposição de lignina. Descrição das estruturas: floema (f), xilema (x), grupo de fibras (gf) e canais laticíferos (cl). Aumento A, B, C, D = 37,5 X; a, b, c, d = 150 X.

\section{REFERÊNCIAS BIBLIOGRÁFICAS}

BUCHANAN, B. B.; GRUISSEN, W.; JONES, R. L. Biochemistry and molecular biology of plants. Rockville: American Society of Plant Physiologists, 2000. 1.367p.

CERQUEIRA, R. C. Avaliação de características pós-colheita de genótipos de bananeira (Musa spp.). 2000. 60f. Dissertação (Mestrado em Ciências Agrárias) - Universidade Federal da Bahia, Cruz das Almas, 2000.

CERQUEIRA, R.C.; SILVA, S. O.; MEDINA, V. M. Características póscolheita de frutos de genótipos de bananeira (Musa spp.). Revista Brasileira de Fruticultura, Jaboticabal, v. 24, n. 3, p. 654-657, 2002.

DADZIE, B. K.; ORCHARD, J. E. Routine post-harvest screening of banana/plantain hybrids: criteria and methods. Inibap Technical Guidelines 2. Montpellier: International Network for the Improvement of Banana and Plantains, 1997. 63p.

JOHANSEN, D. A. Plant microtechnique. The Maple Press Company: 
New York, 1940. 523p.

KRAUS, J. E.; ARDUIN, M. Manual básico de métodos em morfologia vegetal. Rio de Janeiro : Universidade Federal Rural do Rio de Janeiro, 1997. 198p.

LICHTEMBERG, L. A. Colheita e pós-colheita de banana. Informe Agropecuário, Belo Horizonte, v. 20, n. 196, p. 73-90, 1999.

MULAS, M.; LAFUENTE, M. A.; ZACARIAS, L. Lignin and gum deposition in wounded 'Oroval' clementines as affected by chilling and peel water content. Postharvest Biology and Technology,
Amsterdam, v. 7, p. 243-251, 1996

NEW, S.; MARRIOTT, J. Factores affecting the development of 'finger drop' in bananas after ripening. Journal of Food Technology, Oxford, v. 18, n. 2, p. 241-250, 1983.

PEREIRA, M. C. T. Caracterização, anatomia do pedicelo, fisiologia e redução do despencamento natural de bananas após a colheita. 2002. 79f. Tese (Doutorado em Fitotecnia) - Universidade Federal de Viçosa, Viçosa, 2002. 